\title{
Association between Full Electronic Medical Record System Adoption and Drug Use: Antibiotics and Polypharmacy
}

\author{
Young-Taek Park ${ }^{1}$, Donghwan Kim ${ }^{2}$, Rae Woong Park ${ }^{3}$, Koray Atalag ${ }^{4}$, In Ho Kwon ${ }^{5}$, Dukyong Yoon ${ }^{3}$, \\ Mona Choi ${ }^{6}$ \\ 'Department of Information and Communication Technology, Health Insurance Review and Assessment Service, Wonju, Korea \\ ${ }^{2}$ Research Institute for Health Insurance Review and Assessment, Health Insurance Review and Assessment Service, Wonju, Korea \\ ${ }^{3}$ Department of Biomedical Informatics, Ajou University School of Medicine, Suwon, Korea \\ ${ }^{4}$ Auckland Bioengineering Institute, The University of Auckland, Auckland, New Zealand \\ ${ }^{5}$ Department of Emergency Medicine, Dong-A University College of Medicine, Busan, Korea \\ ${ }^{6}$ Mo-Im Kim Nursing Research Institute, College of Nursing, Yonsei University, Seoul, Korea
}

Objectives: We investigated associations between full Electronic Medical Record (EMR) system adoption and drug use in healthcare organizations (HCOs) to explore whether EMR system features such as electronic prescribing, medicines reconciliation, and decision support, might be related to drug use by using the relevant nation-wide data. Methods: The study design was cross-sectional. Survey data of the level of adoption of EMR systems were collected for the Organization for Economic Co-operation and Development benchmarking information and communication technologies (ICT) study between November 2013 and January 2014, in Korea. Survey respondents were hospital chief information officers and medical practitioners in primary care clinics. From the national health insurance administrative dataset, two outcomes, the rate of antibiotic prescription and polypharmacy with $\geq 6$ drugs, were extracted. Results: We found that full EMR adoption showed a $16.1 \%$ lower antibiotic drug prescription than partial adoption including paper-based medical charts in the hospital only $(p=0.041)$. Between EMR adoption status and polypharmacy prescription, only those clinics which fully adopted EMR showed significant associations with higher polypharmacy prescriptions $(36.9 \%, p=0.001)$. Conclusions: The findings suggested that there might be some confounding effects present and sophisticated ICT may provide some benefits to the quality of care even with some mixed results. Although a negative relationship between full EMR system adoption and antibiotic drug use was only significant in hospitals, EMR system functions searching drugs or listing specific patients might facilitate antibiotic drug use reduction. Positive relationships between full EMR system adoption and polypharmacy rate in general hospitals and clinics, but not hospitals, require further research.

Keywords: Electronic Health Records, Health Care Evaluation Mechanisms, Quality of Health Care, Anti-Bacterial Agents, Polypharmacy

Submitted: September 22, 2019

Revised: 1st, December 8, 2019; 2nd, December 29, 2019

Accepted: January 20, 2020

\section{Corresponding Author}

Mona Choi

Mo-Im Kim Nursing Research Institute, College of Nursing, Yonsei University, 50 Yonsei-ro, Seodaemun-gu, Seoul 03722, Korea. Tel: +82-2-22283341, E-mail: monachoi@yuhs.ac (https://orcid.org/0000-0003-4694-0359)

This is an Open Access article distributed under the terms of the Creative Commons Attribution Non-Commercial License (http://creativecommons.org/licenses/by-nc/4.0/) which permits unrestricted non-commercial use, distribution, and reproduction in any medium, provided the original work is properly cited.

(c) 2020 The Korean Society of Medical Informatics 


\section{Introduction}

Antibiotics are essential to help the immune system eliminate certain pathogenic bacteria and a wide range of medications are currently used for medical care [1]. However, high antibiotic use is a serious problem because it causes an increase in antibiotic resistant bacteria. Additionally, prescribing multiple medicines to patients known as 'polypharmacy' is a serious concern in medical care because of increased chances of drug-drug interactions and other adverse effects [2]. Therefore, many countries are interested in monitoring antibiotic use.

Regarding antibiotics, the rate of antibiotic use varies considerably depending on the type of medical care or the location of the healthcare facilities. A study using sampled ambulatory care visits found that the rate of antibiotic use was $12.6 \%$ in the United States (US) [3]. However, another study showed that the rate of antibiotic use was $44.5 \%-51.4 \%$ in emergency departments (ED) depending on the state in the US [4]. The annual prevalence rate of antibiotic use was $29 \%$ (29 users per 100 patients) in the United Kingdom, which was measured by dividing the number of patients prescribed an antibiotic by the total number of patients in every database mid-year in 2009 [5].

For polypharmacy, the World Health Organization defined it as the administration of many drugs at the same time or the administration of an excessive number of drugs [6]. Previous studies suggest different thresholds of the count of concurrent medication taken, e.g., 5 or more [7], 6 or more [8], or 10 or more medications [9]. Approximately 15\% of adults $\geq 20$ years were prescribed with 5 or more drugs simultaneously for 30 days in 2011-2012 in a study using the US National Health and Nutrition Examination Survey data [10]. A study conducted in England found that 22\% of patients were dispensed with 5 or more drugs in 2010 [2].

Various factors are affecting the use of antibiotics and polypharmacy. Currently, providers' behavioral and recipients' clinical parameters have been accepted as the main factors affecting the rate of antibiotics use and polypharmacy [1113]. However, other potential factors have not been fully investigated, such as the relationship between Electronic Medical Record/Health Record (EMR/EHR, hereafter EMR) systems adoption and antibiotic use and polypharmacy, which is the subject of this study.

EMR systems are increasingly used in healthcare settings. The adoption rate of EMR systems in the US was approximately 85\% in hospitals as of December 2015 [14]. According to the European Union, the reported adoption rates of
EMR systems are $85 \%$ and $93 \%$ in hospitals and clinics, respectively $[15,16]$. The EMR adoption rates, including those of health care organizations (HCOs) with partial implementations, were $96.3 \%$ and $95.7 \%$ in hospitals and clinics as of December 2013 in Korea [17].

The main functions of the EMR systems are to document patient care electronically and provide this information at the point of care. Most EMR systems provide other functions such as computer-based order entry, decision support, and analytics. Advanced medication management functions are available for recommending specific drugs based on clinical indications and any known interactions as well as dispatching reminders and alerts to inform the care team of any changes in clinical parameters or evidence-based changes. EMR systems allow searching for patients on specific drugs or monitoring of possible drug-drug interactions $[18,19]$. Healthcare providers can retrieve prescriptions, as well as dispense and administer drugs using the EMR systems. Healthcare providers can also obtain automated recommendations for drug choices and other important tasks such as medicine review and reconciliation, which ultimately lead to more appropriate drug use [20]. These functionalities and actionable information support healthcare providers in making critical decisions and in adhering to organizational procedures and processes [21], which in turn, may impact prescription quality.

Based on these findings, we formulated a hypothesis that full EMR system adoption would improve drug use by lowering antibiotic prescription and polypharmacy rates compared with other systems including paper-based medical charts. Full EMR system adoption means an electronic system that is used to store and manage for all patient health information based on the guide from the Organization for Economic Co-operation and Development (OECD) [22]. The institutional theory may explain the proposed hypothesis. The theory posits that technological innovations improve efficiency and performance, and the government implements regulations on these technologies such as their adoption and encourages or requires adherence to specific guidelines. Finally, these institutions or regulations affect organizations [23-26]. There are regulations, and rules regarding the use of EMR systems (e.g., healthcare information exchanges) [27]. This is because EMR systems improve the efficiency of various aspects of medical care such as quality of care including rational drug use. Generally, a reduction in the use of antibiotics and polypharmacy is considered as quality care and recommended by governments. Thus, to examine whether full EMR systems are associated with lower antibiotic use 
and polypharmacy rates would be meaningful.

A systematic literature review reported the impact of an EHR system on the quality of drug use and found that higher guideline adherence was observed when the EHR system was used compared to the control group that did not use it [28]. A study investigated whether quality standards for good diabetic care in practice were achieved in the EMR system adoption and paper-based practice settings. It found that diabetes care standards were significantly of higher quality in sites with EHR system adoption than paper-based sites [29]. Although there are some reports that EMR adoption status was not associated with any quality of care measures [30,31], the overall evidence warrants more research into the effects of EMR system adoption.

Very few studies have investigated the relationship between drug use (particularly, antibiotics and polypharmacy) and EMR system adoption status. Therefore, the objective of this study was to investigate how EMR system adoption levels are associated with the quality of drug prescription and utilization of drugs in Korea. Our hypothesis was that HCOs with a high level of EHR adoption are associated with lower rates of antibiotic drug use and polypharmacy prescriptions than those with lower EHR adoption levels. Thus, these results can also inform policymakers on the effectiveness of healthcare information and communication technologies (ICT).

\section{Methods}

\section{Study Design}

This study used a cross-sectional design and in conducting the survey, we asked whether each HCO had adopted a full or partial EMR system or was using paper-based medical charts. For simplicity in interpreting the study findings, we used a simple design to compare HCOs that had fully adopted the EMR system with those that had partial EMR systems or paper-based medical charts.

As the main independent variable in this study, we measured two levels of EMR system implementation: full EMR system versus others. We assumed full EMR system adoption as one in which patients' data were mainly stored and electronically whereas the 'others' were both partial EMR systems and paper-based medical charts. The partial EMR system was defined as one some patients' records are stored and managed electronically and some are on paper [22].

\section{Data Collection}

The study used both a nationwide survey data and administrative data from the Health Insurance Review and
Assessment Service (HIRA) in Korea. HIRA is one of the government agencies running the national health insurance program that provides professional health insurance review and assessment services in Korea [32].

For the main independent variable, that is, the level of adoption of EMR systems, we evaluated full or partial EMR systems or paper-based medical records. The data retrieved from the survey conducted for the OECD benchmarking ICT study, which is one of the numerous OECD initiatives $[22,33]$. The survey instrument was developed by the OECD benchmarking ICT team. In addition to the original instrument, the HIRA added other questions for purposes such as business. There were 280 general hospitals, 1,371 hospitals, and 26,063 clinics as of September 1,2013. As study subjects, all general hospitals were included while we randomly selected 288 of the 1,371 hospitals and 905 of the 26,063 clinics with $5 \%$ and $3 \%$ sampling errors, respectively. The HIRA conducted the surveys following the methodological guidelines of the OECD from November 19, 2013 to January 10, 2014. The respondents were chief information officers (CIO) in hospitals and primary care practitioners in ambulatory clinics.

For the survey method, the HIRA contracted a professional survey company with a nationwide survey network. The company hired interviewers and instructed them to visit clinics where the medical providers were asked to answer the questionnaires. The HIRA, Ministry of Health and Welfare, and the Korean Hospital Association indirectly supported this survey through official administrative letters and advertisements in their networks. There were 266 respondents at the general hospitals with a $95 \%$ response rate, whereas the hospitals and clinics had 288 and 906 (response rate, 80.4\% and $67.2 \%$ ) respondents, respectively.

Regarding the HIRA administrative data, we used data coming from the Drug Utilization Index-linked Autonomy Program (DUILAP), which monitors specific drug utilization such as antibiotics, injectables, and polypharmacy. If the HIRA detects hospitals or clinics with concerning practices such a high percentage of antibiotic drug use, a warning notice is issued. Thus, hospitals and clinics could autonomously maintain an appropriate level of antibiotic drug use.

Lastly, this study linked the survey data with HIRA administrative data and selected final study subjects that had both the survey and administrative information. The number of original study subjects of the OECD survey was slightly reduced. Furthermore, to determine the percentage of antibiotic prescription, 264 general hospitals, 244 hospitals, and 732 clinics were included. For the percentage of polyphar- 
macy prescription analysis, 264 general hospitals, 258 hospitals, and 839 clinics were included.

The Institutional Review Board of HIRA approved this study (IRB No. 2017-029-001).

\section{Outcome and Covariate Measures}

This study hypothesized that the EMR systems would be related to the use of antibiotic drugs and polypharmacy. The study selected the available two main outcome variables: the rate of prescription of antibiotics for outpatients with upper acute respiratory tract infection and rate of polypharmacy prescription, which were descriptively defined as the percentage of antibiotic prescriptions and prescriptions with $\geq 6$ drugs, respectively in each HCO. The former was calculated by dividing the number of antibiotic prescriptions by the total number of prescriptions and the latter by dividing the number of prescriptions with $\geq 6$ drugs by the total number of prescriptions in each HCO. Both indices were targeting for outpatients. Regarding the diagnosis codes for the patients with upper acute respiratory tract infection, HIRA had managed the index using the primary diagnosis code in which the codes of the Korean Standard Classification of
Diseases (KCD) are from J00 to J06. This data was retrieved from HIRA data warehouse systems based on each HCO, and the average rate per quarter was calculated for 2 years from January 1, 2014 to December of 2015. This means that the rate was averaged for 8 quarters for 2 years.

The measures were descriptively defined following the OECD guidelines. To control for other factors that might affect the main study results, we selected several covariates from the HIRA data warehouse system, which are presented in Table 1.

\section{Statistical Analysis}

The unit of analysis in this study was the HCO: general hospitals, hospitals, and clinics. Furthermore, this study differentiated general hospitals from other hospitals because Korean Medical Service Act [34] sets forth different establishment requirements for general hospitals with $>100$ beds and at least a minimum of five medical specialties. This study excluded the tertiary hospitals from the analysis because they had unique features such as having the college of medicine, 27 specialized medical departments, and so on. Hospitals differ from clinics in that they should have more

Table 1. Description of major variables and covariates including data source

\begin{tabular}{|c|c|c|}
\hline Variable & Measures & Data sources $^{\mathrm{a}}$ \\
\hline \multicolumn{3}{|l|}{ Outcome variables } \\
\hline Antibiotics & $\begin{array}{l}\text { Percentage (\%) of antibiotic prescriptions per quarter (average for } 2 \text { years: } 2014 \text {, } \\
\text { 2015) }\end{array}$ & 1 \\
\hline Polypharmacy & $\begin{array}{l}\text { Percentage (\%) of prescriptions with } \geq 6 \text { drugs per quarter (average for } 2 \text { years: } \\
2014,2015 \text { ) }\end{array}$ & 1 \\
\hline \multicolumn{3}{|l|}{ Main independent variables } \\
\hline EMR adoption status & $\begin{array}{l}\text { Measured with full EMR system or partial (using paper charts and electronic } \\
\text { chart or paper chart only) EMR systems }\end{array}$ & 2 \\
\hline \multicolumn{3}{|l|}{ Covariates } \\
\hline Location & $\begin{array}{l}\text { Measured with a special district (SD) and mega metro cities (MMC) or not. SD } \\
\text { only included Seoul, and MMC included all mega-metropolitan cities with } \\
\text { population of more than a million }\end{array}$ & 3 \\
\hline Number of physicians & Number of physicians & 2,3 \\
\hline Foundation & Private versus public & 3 \\
\hline Affiliation & $\begin{array}{l}\text { Having any contracts with other hospitals or clinics for purchasing medical sup- } \\
\text { plies or patient referrals }\end{array}$ & 2 \\
\hline ICT staff or ICT department & $\begin{array}{l}\text { Number of staff of ICT (general hospitals); having ICT department (hospitals } \\
\text { and clinics) }\end{array}$ & 2 \\
\hline Beds & Number of beds (general hospitals, hospitals); having beds or not (clinics) & 3 \\
\hline
\end{tabular}

EMR: Electronic Medical Record, ICT: information and communication technology.

aData sources: "1" a program on the Health Insurance Review and Assessment Service (HIRA) drug use evaluation, "2" Organization for Economic Co-operation and Development Benchmarking ICT study, and “3” HIRA's administrative data. 
than 30 beds.

This study tabulated the HCO covariates as the main independent variable measured by types of EMR systems based on two outcome variables separately and conducted tests such as the chi-square test of independence and $t$-test of mean differences. For the main statistical analysis, which was the association of the main independent variables (EMR types) with two outcome variables (antibiotic use, polypharmacy prescriptions), we used a generalized linear model with the GENMOD procedure having the option of log and link functions in SAS program version 9.4.

\section{Results}

Table 2 shows the general characteristics of general hospitals, hospitals, and clinics based on the types of EMR system adopted. Antibiotic drug use rate was lower in the full adoption system than in the partial adoption system including paperbased medical charts, and the difference was statistically significant in hospitals $(p=0.006)$. However, partial EMR

Table 2. General characteristics of study subjects by type of healthcare organization

\begin{tabular}{|c|c|c|c|c|c|c|c|}
\hline \multirow{3}{*}{ Type } & \multirow{3}{*}{ Clinic characteristic } & \multicolumn{3}{|c|}{ Antibiotic prescriptions } & \multicolumn{3}{|c|}{ Polypharmacy prescriptions } \\
\hline & & \multicolumn{3}{|c|}{ Partial EMR } & \multicolumn{3}{|c|}{ Partial EMR } \\
\hline & & Full EMR & $\begin{array}{c}\text { and paper } \\
\text { chart }\end{array}$ & $p$-value & Full EMR & $\begin{array}{c}\text { and paper } \\
\text { chart }\end{array}$ & $p$-value \\
\hline \multirow{9}{*}{$\begin{array}{l}\text { General } \\
\text { hospitals }\end{array}$} & Total $($ antibiotics $\mathrm{n}=264$; polypharmacy $\mathrm{n}=264)$ & 193 & 71 & - & 193 & 71 & - \\
\hline & $\mathrm{SD}$ and $\mathrm{MMC}(\%)$ & 41.9 & 35.2 & 0.321 & 41.9 & 35.2 & 0.321 \\
\hline & Number of physicians & 47.3 & 40.2 & 0.145 & 47.3 & 40.2 & 0.145 \\
\hline & Private foundation (\%) & 26.9 & 19.7 & 0.229 & 26.9 & 19.7 & 0.229 \\
\hline & Affiliated with other hospitals (\%) & 77.2 & 76.1 & 0.845 & 77.2 & 76.1 & 0.845 \\
\hline & Number of staff in ICT department & 5.2 & 3.9 & 0.087 & 5.2 & 3.9 & 0.087 \\
\hline & Number of beds & 427.0 & 387.1 & 0.160 & 427.0 & 387.1 & 0.160 \\
\hline & Antibiotic drug use/quarter (\%) & 37.8 & 38.8 & 0.607 & - & - & - \\
\hline & Polypharmacy prescription (\%) & - & - & - & 16.1 & 16.2 & 0.926 \\
\hline \multirow[t]{9}{*}{ Hospitals } & Total (antibiotics $n=244 ;$ polypharmacy $n=258$ ) & 160 & 84 & - & 172 & 86 & - \\
\hline & SD and MMC (\%) & 51.3 & 38.1 & 0.050 & 49.4 & 40.7 & 0.186 \\
\hline & Number of physicians & 8.2 & 6.1 & 0.003 & 8.0 & 6.1 & 0.003 \\
\hline & Private foundation (\%) & 76.3 & 78.6 & 0.682 & 72.1 & 76.7 & 0.424 \\
\hline & Affiliated with other hospitals (\%) & 54.4 & 46.4 & 0.238 & 53.5 & 50.0 & 0.597 \\
\hline & ICT department with beds (\%) & 41.9 & 20.2 & 0.001 & 43.6 & 19.8 & $<0.001$ \\
\hline & Number of beds & 138.3 & 139.5 & 0.926 & 152.6 & 133.7 & 0.168 \\
\hline & Antibiotic drug use/quarter (\%) & 37.6 & 47.0 & 0.006 & - & - & - \\
\hline & Polypharmacy prescription (\%) & - & - & - & 11.4 & 12.2 & 0.619 \\
\hline \multirow[t]{9}{*}{ Clinics $^{\mathrm{a}}$} & Total (antibiotics $n=732 ;$ polypharmacy $n=839$ ) & 510 & 222 & - & 588 & 251 & - \\
\hline & SD and MMC (\%) & 47.1 & 54.5 & 0.064 & 48.6 & 55.0 & 0.093 \\
\hline & Number of physicians & 1.3 & 1.4 & 0.491 & 1.3 & 1.4 & 0.389 \\
\hline & Private foundation (\%) & 98.2 & 96.9 & 0.238 & 98.5 & 97.2 & 0.222 \\
\hline & Affiliated with other hospitals (\%) & 26.3 & 21.6 & 0.181 & 26.0 & 21.5 & 0.166 \\
\hline & ICT department (\%) & 2.0 & 2.3 & 0.798 & 1.7 & 2.4 & 0.504 \\
\hline & Having beds (\%) & 48.2 & 58.1 & 0.014 & 45.8 & 57.0 & 0.003 \\
\hline & Antibiotic drug use/quarter (\%) & 42.7 & 43.9 & 0.606 & - & - & - \\
\hline & Polypharmacy prescription (\%) & - & - & - & 12.6 & 9.0 & $<0.001$ \\
\hline
\end{tabular}

EMR: Electronic Medical Record, SD: special district, MMC: mega metro cities, ICT: information and communication technology. ${ }^{a}$ Most of clinics are private in Korea. 
and paper-based medical charts had a lower percentage of prescriptions with $>6$ in clinics $(p<0.001)$ than other HCOs. Regarding organizational covariates, hospitals with full EMR adoptions had more physicians $(p=0.003)$ and a higher percentage with an ICT department $(p=0.001)$ in both antibiotics and polypharmacy. Clinics with beds were more likely to have a partial EMR and paper-charts, which was statistically significant in both antibiotics $(p=0.014)$ and polypharmacy $(p=0.003)$.

Association of full EMR system adoption with antibiotic drug use rate is described in Table 3, which shows the regression results after controlling for clinic covariates. All three groups of HCOs (general hospitals, hospitals, and clinics) with full EMR systems had lower rates of antibiotic drug use than those with partial EMR and paper-charts. However, the relationship was only statistically significant in hospital groups. Hospitals with full EMR systems had a 16.1\% lower rate $(\exp (-0.176)=0.839)$ of antibiotic drug use than that of the partial EMR and paper-chart groups $(16.1 \%$; $95 \% \mathrm{CI}$, $0.7-29.1 ; p=0.041$ ).

Table 4 shows the results of the regression analysis of the association of polypharmacy prescription with full EMR system adoption after controlling for several $\mathrm{HCO}$ covariates. Unlike the proposed hypothesis, general hospitals and clinics with full EMR system had higher rates of the prescription of polypharmacy than those without full EMR. Especially, clinics with full EMR systems had higher rates of prescription of polypharmacy than those with partial EMR and papercharts. Clinics with full EMR systems had a $36.9 \%$ higher rate $(\exp (0.314)=1.369)$ of polypharmacy than HCOs with

Table 3. Association of EMR system adoption with prescriptions of antibiotics

\begin{tabular}{|c|c|c|c|c|c|c|}
\hline \multirow[t]{2}{*}{ Variable } & \multicolumn{2}{|c|}{$\begin{array}{l}\text { General hospitals } \\
(n=264)\end{array}$} & \multicolumn{2}{|c|}{$\begin{array}{l}\text { Hospitals } \\
(\mathrm{n}=261)\end{array}$} & \multicolumn{2}{|c|}{$\begin{array}{c}\text { Clinics } \\
(n=780)\end{array}$} \\
\hline & Coefficient & $p$-value & Coefficient & $p$-value & Coefficient & $p$-value \\
\hline SD and MMC (ref: no SD and MMC) & -0.014 & 0.796 & 0.047 & 0.561 & -0.001 & 0.997 \\
\hline Number of physicians & -0.005 & 0.001 & -0.020 & 0.020 & 0.002 & 0.960 \\
\hline Private foundation (ref: public) & 0.076 & 0.242 & -0.125 & 0.216 & -0.023 & 0.918 \\
\hline Affiliation status (ref: no affiliation) & 0.064 & 0.308 & -0.106 & 0.187 & -0.002 & 0.978 \\
\hline ICT staffs/department ${ }^{a}$ (ref: no ICT department) & -0.005 & 0.243 & 0.024 & 0.793 & -0.134 & 0.555 \\
\hline Beds $^{\mathrm{b}}$ & 0.001 & 0.030 & 0.001 & 0.408 & 0.039 & 0.536 \\
\hline Full EMR system adoption (ref: partial EMR and paper charts) & -0.014 & 0.814 & -0.176 & 0.041 & -0.024 & 0.723 \\
\hline
\end{tabular}

EMR: Electronic Medical Record, SD: special district, MMC: mega metro cities, ICT: information and communication technology.

${ }^{a}$ Number of ICT staff in general hospitals; percentage (\%) with ICT department in hospitals and clinics.

${ }^{b}$ Number of beds in general hospitals, hospitals; whether beds were available or not for clinics (ref $=$ no bed).

Table 4. Association of EMR system adoption with polypharmacy

\begin{tabular}{|c|c|c|c|c|c|c|}
\hline \multirow[t]{2}{*}{ Variable } & \multicolumn{2}{|c|}{$\begin{array}{l}\text { General hospitals } \\
\qquad(n=264)\end{array}$} & \multicolumn{2}{|c|}{$\begin{array}{l}\text { Hospitals } \\
(\mathrm{n}=261)\end{array}$} & \multicolumn{2}{|c|}{$\begin{array}{l}\text { Clinics } \\
(n=780)\end{array}$} \\
\hline & Coefficient & $p$-value & Coefficient & $p$-value & Coefficient & $p$-value \\
\hline SD and MMC (ref: no SD and MMC) & -0.063 & 0.174 & -0.242 & 0.057 & -0.087 & 0.302 \\
\hline Number of physicians & -0.006 & $<0.001$ & -0.023 & 0.056 & -0.036 & 0.373 \\
\hline Private foundation (ref: public) & -0.058 & 0.293 & -0.273 & 0.069 & 0.216 & 0.481 \\
\hline Affiliation status (ref: no affiliation) & -0.054 & 0.313 & -0.137 & 0.278 & 0.081 & 0.404 \\
\hline ICT staffs/department ${ }^{\mathrm{a}}$ (ref: no ICT department) & -0.004 & 0.320 & -0.005 & 0.970 & 0.196 & 0.522 \\
\hline $\mathrm{Beds}^{\mathrm{b}}$ & 0.001 & $<0.001$ & 0.001 & 0.417 & -0.132 & 0.119 \\
\hline Full EMR system adoption (ref: partial EMR and paper charts) & 0.018 & 0.729 & -0.012 & 0.930 & 0.314 & 0.001 \\
\hline
\end{tabular}

EMR: Electronic Medical Record, SD: special district, MMC: mega metro cities, ICT: information and communication technology.

${ }^{a}$ Number of ICT staff in general hospitals; percentage (\%) with ICT department in hospitals and clinics.

${ }^{\mathrm{b}}$ Number of beds in general hospitals and hospitals; whether beds were available or not for clinics (ref $=$ no bed). 
partial EMR and paper-charts (36.9\%; 95\% CI, 14.3-63.9; $p$ $=0.001)$.

\section{Discussion}

This study investigated the association of EMR system adoption levels with antibiotics drug use and polypharmacy. EMR adoption status was measured in two types of systems: the full EMR system and the others. The drug use was measured as the rates of antibiotic prescription and polypharmacy prescription with $\geq 6$ drugs. Functions of EMR systems, such as searching or listing specific patients or drugs, enabled us to predict potential relationships between EMR system adoption levels and quality of drug use, which is reduced use of antibiotics and polypharmacy.

The study revealed a negative association between EMR status and the rate of antibiotic drug use in all three groups of HCOs; however, only the hospital results were statistically significant. This result supports the initial hypothesis of this study that various functions of the EMR system would diminish the use of antibiotics. Our study results agree with those of previous studies in which the quality of care increased as the EMR system adoption levels increased $[28,29,35,36]$. The prescription rate of antibiotics was approximately $40 \%$, which was the same as that reported in a previous study conducted in the US [4]. This may be because the severity of patients' conditions was almost similar where the former was in outpatients with upper acute respiratory tract infection and the latter were patients who visited the ED.

Furthermore, in this study, we also expected an association between polypharmacy and the level of EMR system adoption because EMR systems feature increased information processing of good practices related to the volume of drugs. Functions of EMR systems would provide previous and current information on patient drug use to doctors, which would diminish the volume of drugs prescribed. However, in contrast to our expectation, the initial hypothesis was only supported in hospitals, but the relationship was not statistically significant. Moreover, the full EMR system had higher rates of polypharmacy with $\geq 6$ drugs the other systems did in general hospitals and clinics. Especially, the full EMR system had a statistically significantly higher rate of polypharmacy in clinics than the partial EMR and paper-chart systems did.

To logically explain our polypharmacy study results, we applied one of the arguments of the contingency theory. Galbraith $[25,37]$ argued that when organizations face the need for information processing, they should choose to either reduce their information processing requirement or increase the capacity to process information. Examples of the former and the latter are creating slack resources (e.g., lowering the objectives) and hiring more staff or adopting EMR systems. Thus, the rate of polypharmacy may increase as the level of EMR system adoption increases. Several empirical studies might support this argument, such as one showing that an EMR system with point-of-care reminders helped medical providers to choose combination drugs and these EMR system functions saved cost by encouraging the use of cheaper combination drugs for patients [38]. According to a study that investigated the association of EMR system sophistication with preventive healthcare resources for women, ordering healthcare tests increased as the EMR systems became more sophisticated from minimal basic to full EMR systems [39]. For example, the breast examination rate of providers with no or minimal EMR system was $20.27 \%$ and $34.96 \%$, respectively, whereas that of providers with a full EMR system was $44.98 \%$ [39]. Thus, the polypharmacy analysis results in clinics might align with these previous study results. Although some of the study results differed slightly from our initial expectations, it is worth noting that full EMR systems may not necessarily markedly improve health care levels because the study results showed contrasting effects. For example, a study found that hospital EDs with full EMR systems had 22.4\% lower length of stay than EDs with minimal or no EMR did [40]. Another observational study assessing physician-patient encounters before and after the implementation of an EMR system in an outpatient clinic found no difference in the number of laboratory tests ordered [41].

Previous empirical studies show the negative relationship between EMR systems and the quality of drug use. Standalone e-prescribing or those integrated with an EMR system were shown to significantly reduce adverse drug events compared to paper-based prescriptions, as determined by parameters such as dosing errors and inappropriate abbreviations [35]. Another study also investigated the association between the level of EHR system implementation (EHR system adoption vs. paper-chart only) and conformity of diabetic care and found that the conformity of practice with EHR systems was modestly higher than that without EHR systems, for three of the seven qualities measured [36].

This study has limitations including the fact that the main independent variable was from the survey data of the nationwide survey for the OECD bench-marking study. Furthermore, the records used were based on the memories of ICT department managers and, there might have been recalling 
bias from the respondents; thus, future studies should use more objective measures of EMR system adoption by verifying its installation. Second, the interpretation of the study results would be limited in Korea because the results may differ depending on the study environments. Therefore, we hope that there would be some international complementary investigations on this topic. Third, although antibiotic drug usages and polypharmacy prescriptions are related to the severity of patients and the number of diagnoses of patients, this study could not include those variables. This fact might result in mixed effects. We hope that further studies could control these confounding effects. Additionally, the adoption of EMR continued after the survey period and that adoption status of HCOs was not captured during the outcome data period. Lastly, this study used a cross-sectional design, which has limitations in investigating some causal relationship. Thus, longitudinal studies to further investigate the relationship between EMR systems and drug use would be expedient. The EHR system, when properly implemented, can improve the quality of healthcare by increasing time efficiency and guideline adherence and reducing medication errors and adverse drug events $[28,29]$.

To expand the knowledge of the unknown effects of EMR systems and compensate for the limitations of our present study, we suggest that further studies using different designs are necessary to confirm whether the results would be similar using a different data source. In addition, it would be important to further identify the specific aspects of EMR systems that reduce or increase the quality and volume of medications. HIRA changed the evaluation system of antibiotics use in July of 2016 [42], which may have an influence on changing the behavior of antibiotics prescription in HCOs. Therefore, future research is needed to examine whether this policy change would impact on the antibiotics prescription.

Although this study did not produce any generalizable study results between EMR system adoption level and drug use, we believe that more sophisticated EMR systems would facilitate the reduction of the number of medications prescribed by healthcare providers.

In conclusion, this study investigated whether EMR system adoption status was associated with antibiotic drug use and the volume of drug use. There might be some confounding effects which were not taken into consideration in this study. Even with some mixed results a significant negative relationship between full EMR system adoption and antibiotic drug use only in hospitals, EMR system functions such as searching drugs or listing specific patients might facilitate antibiotic drug use reduction. Positive relationships between full EMR system adoption and polypharmacy rate in general hospitals and clinics, but not hospitals, require further research. This study suggests that sophisticated ICT may provide some benefits to the quality of care.

\section{Conflict of Interest}

No potential conflict of interest relevant to this article was reported.

\section{ORCID}

Young-Taek Park (http://orcid.org/0000-0002-7574-4165)

Donghwan Kim (http://orcid.org/0000-0003-3083-4228)

Rae Woong Park (http://orcid.org/0000-0003-4989-3287)

Koray Atalag (http://orcid.org/0000-0003-0517-4803)

In Ho Kwon (https://orcid.org/0000-0002-2518-6951)

Dukyong Yoon (https://orcid.org/0000-0003-1635-8376)

Mona Choi (https://orcid.org/0000-0003-4694-0359)

\section{References}

1. Ventola CL. The antibiotic resistance crisis: part 1: causes and threats. P T 2015;40(4):277-83.

2. Mair A, Fernandez-Llimos F; SIMPATHY Consortium. Polypharmacy management programmes: the SIMPATHY Project. Eur J Hosp Pharm 2017;24(1):5-6.

3. Fleming-Dutra KE, Hersh AL, Shapiro DJ, Bartoces M, Enns EA, File TM Jr, et al. Prevalence of inappropriate antibiotic prescriptions among US Ambulatory Care Visits, 2010-2011. JAMA 2016;315(17):1864-73.

4. Safdar N, Tape TG, Fox BC, Svenson JE, Wigton RS. Factors affecting antibiotic prescribing for acute respiratory infection by emergency physicians. Health 2014;6:77480.

5. Brauer R, Ruigomez A, Downey G, Bate A, Garcia Rodriguez LA, Huerta C, et al. Prevalence of antibiotic use: a comparison across various European health care data sources. Pharmacoepidemiol Drug Saf 2016;25 Suppl 1:11-20.

6. World Health Organization. A glossary of terms for community health care and services for older persons [Internet]. Geneva, Switzerland: World Health Organization; 2004 [cited at 2020 Jan 30]. Available from: https:// apps.who.int/iris/bitstream/handle/10665/68896/WHO_ WKC_Tech.Ser._04.2.pdf?sequence=1\&isAllowed $=y$.

7. Haider SI, Johnell K, Weitoft GR, Thorslund M, Fast- 
bom J. The influence of educational level on polypharmacy and inappropriate drug use: a register-based study of more than 600,000 older people. J Am Geriatr Soc 2009;57(1):62-9.

8. Bushardt RL, Massey EB, Simpson TW, Ariail JC, Simpson KN. Polypharmacy: misleading, but manageable. Clin Interv Aging 2008;3(2):383-9.

9. Hovstadius B, Astrand B, Petersson G. Assessment of regional variation in polypharmacy. Pharmacoepidemiol Drug Saf 2010;19(4):375-83.

10. Kantor ED, Rehm CD, Haas JS, Chan AT, Giovannucci EL. Trends in prescription drug use among adults in the United States From 1999-2012. JAMA 2015;314(17):1818-31.

11. McKay R, Mah A, Law MR, McGrail K, Patrick DM. Systematic review of factors associated with antibiotic prescribing for respiratory tract infections. Antimicrob Agents Chemother 2016;60(7):4106-18.

12. Choi KH, Park SM, Lee JH, Kwon S. Factors affecting the prescribing patterns of antibiotics and injections. J Korean Med Sci 2012;27(2):120-7.

13. Li P, Metlay JP, Marcus SC, Doshi JA. Factors associated with antimicrobial drug use in medicaid programs. Emerg Infect Dis 2014;20(5):829-32.

14. Henry J, Pylypchuk Y, Searcy T, Patel V. Adoption of electronic health record systems among US non-federal acute care hospitals: 2008-2015 [Internet]. Washington (DC): The Office of the National Coordinator for Health Information Technology (ONC); 2016 [cited at 2020 Jan 30]. Available from: https://www.healthit.gov/ sites/default/files/briefs/2015_hospital_adoption_db_ v17.pdf.

15. Sabes-Figuera R, Maghiros I. European hospital survey: benchmarking deployment of e-Health services (20122013) [Internet]. Seville, Spain: European Commission; 2013 [cited at 2020 Jan 30]. Available from: https://www. key4biz.it/files/000261/00026119.pdf.

16. Codagnone C, Lupianez-Villanueva F. Benchmarking deployment of eHealth among general practitioners (2013) [Internet]. Luxembourg: European Commission; 2013 [cited at 2020 Jan 30]. Available from: http://ec.europa. eu/newsroom/dae/document.cfm?doc_id=4897.

17. Park YT, Han D. Current status of electronic medical record systems in hospitals and clinics in Korea. Healthc Inform Res 2017;23(3):189-198.

18. Nimbal V, Segal JB, Romanelli RJ. Estimating generic drug use with electronic health records data from a health care delivery system: implications for quality improvement and research. J Manag Care Spec Pharm 2016;22(10):1143-7.

19. Phansalkar S, Desai AA, Bell D, Yoshida E, Doole J, Czochanski $\mathrm{M}$, et al. High-priority drug-drug interactions for use in electronic health records. J Am Med Inform Assoc 2012;19(5):735-43.

20. Shemeikka T, Bastholm-Rahmner P, Elinder CG, Veg A, Tornqvist E, Cornelius B, et al. A health record integrated clinical decision support system to support prescriptions of pharmaceutical drugs in patients with reduced renal function: design, development and proof of concept. Int J Med Inform 2015;84(6):387-95.

21. Holroyd-Leduc JM, Lorenzetti D, Straus SE, Sykes L, Quan H. The impact of the electronic medical record on structure, process, and outcomes within primary care: a systematic review of the evidence. J Am Med Inform Assoc 2011;18(6):732-7.

22. Organization for Economic Co-operation and Development. Draft OECD guide to measuring ICTs in the health sector [Internet]. Paris, France: Organization for Economic Co-operation and Development; 2015 [cited at 2020 Jan 30]. Available from: https://www.oecd.org/ health/health-systems/Draft-oecd-guide-to-measuringicts-in-the-health-sector.pdf.

23. Meyer JW, Rowan B. Institutionalized organizations: formal structure as myth and ceremony. Am J Sociol 1977;83(2):340-63.

24. DiMaggio PJ, Powell WW. The iron cage revisited: institutional isomorphism and collective rationality in organizational fields. Am Sociol Rev 1983;48(2):147-60.

25. Richard Scott W. Organizations: rational, natural, and open systems. 5th ed. Englewood Cliffs (NJ): PrenticeHall; 2003.

26. Burnett S, Mendel P, Nunes F, Wiig S, van den Bovenkamp H, Karltun A, et al. Using institutional theory to analyse hospital responses to external demands for finance and quality in five European countries. J Health Serv Res Policy 2016;21(2):109-17.

27. Ji H, Yoo S, Heo EY, Hwang H, Kim JW. Technology and policy challenges in the adoption and operation of health information exchange systems. Healthc Inform Res 2017;23(4):314-21.

28. Campanella P, Lovato E, Marone C, Fallacara L, Mancuso A, Ricciardi W, et al. The impact of electronic health records on healthcare quality: a systematic review and meta-analysis. Eur J Public Health 2016;26(1):60-4.

29. Cebul RD, Love TE, Jain AK, Hebert CJ. Electronic health records and quality of diabetes care. N Engl J 
Med 2011;365(9):825-33.

30. Patterson ME, Marken P, Zhong Y, Simon SD, Ketcherside W. Comprehensive electronic medical record implementation levels not associated with 30-day allcause readmissions within Medicare beneficiaries with heart failure. Appl Clin Inform 2014;5(3):670-84.

31. McCullough JS, Christianson J, Leerapan B. Do electronic medical records improve diabetes quality in physician practices? Am J Manag Care 2013;19(2):144-9.

32. Park YT, Yoon JS, Speedie SM, Yoon H, Lee J. Health insurance claim review using information technologies. Healthc Inform Res 2012;18(3):215-24.

33. Zelmer J, Ronchi E, Hypponen H, Lupianez-Villanueva F, Codagnone C, Nohr C, et al. International health IT benchmarking: learning from cross-country comparisons. J Am Med Inform Assoc 2017;24(2):371-9.

34. Medical Service Act, Article 3: Medical Institutions (Jan 28, 2015).

35. Walsh MN, Yancy CW, Albert NM, Curtis AB, Stough WG, Gheorghiade $M$, et al. Electronic health records and quality of care for heart failure. Am Heart J 2010;159(4):635-642.e1.

36. Kaushal R, Kern LM, Barrón Y, Quaresimo J, Abramson EL. Electronic prescribing improves medication safety in community-based office practices. J Gen Intern Med 2010;25(6):530-6.

37. Galbraith JR. Organization design: an information processing view. Interfaces 1974;4(3):28-36.

38. Wells BJ, Lobel KD, Dickerson LM. Using the electronic medical record to enhance the use of combination drugs. Am J Med Qual 2003;18(4):147-9.

39. Tundia NL, Kelton CM, Cavanaugh TM, Guo JJ, Hanseman DJ, Heaton PC. The effect of electronic medical record system sophistication on preventive healthcare for women. J Am Med Inform Assoc 2013;20(2):268-76.

40. Furukawa MF. Electronic medical records and the efficiency of hospital emergency departments. Med Care Res Rev 2011;68(1):75-95.

41. Makoul G, Curry RH, Tang PC. The use of electronic medical records: communication patterns in outpatient encounters. J Am Med Inform Assoc 2001;8(6):610-5.

42. Health Insurance Review \& Assessment Service. Improving utilization of relative resource use measures and low-value care measures for preventing wastes ( $\mathrm{Re}$ port No. G000F81-2017-26) [Internet]. Sejong, Korea: Ministry of Economy and Finance; 2017 [cited at 2020 Jan 30]. Available from: http://alio.go.kr/download. dn?fileNo=2267937. 